BRAVZULIAN JOURNAL

OF MEDICAL AND BIOLOGICAL RESH.ARCH

www.bjournal.com.br
ISSN 0100-879X

Volume 43 (5) 381-496 May 2011

BIOMEDICAL SCIENCES

AND

CLINICAL INVESTIGATION

Braz J Med Biol Res, May 2011, Volume 44(5) 428-437

doi:

Differential behavioral outcomes of 3,4-methylenedioxymethamphetamine (MDMA-ecstasy) in anxiety-like responses in mice

V. Ferraz-de-Paula, D. Stankevicius, A. Ribeiro, M.L. Pinheiro, E.C. Rodrigues-Costa, J.C. Florio,

S.F. Lapachinske, R.L.M. Moreau and J. Palermo-Neto

The Brazilian Journal of Medical and Biological Research is partially financed by

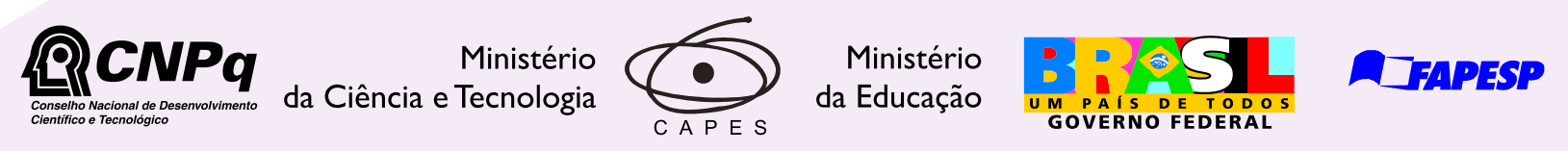

Institutional Sponsors
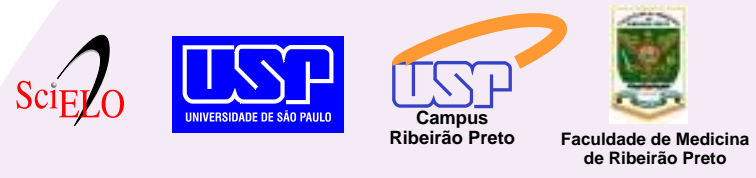
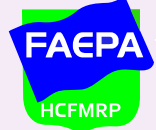

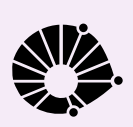

UNICAMP
Ф SHIMADZU

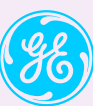

GE Healthcare
Hotsite of proteomics metabolomics developped by:

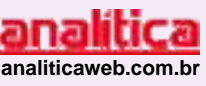




\title{
Differential behavioral outcomes of 3,4-methylenedioxymethamphetamine (MDMA-ecstasy) in anxiety-like responses in mice
}

\author{
V. Ferraz-de-Paula ${ }^{1 *}$, D. Stankevicius ${ }^{1 *}$, A. Ribeiro ${ }^{1}$, M.L. Pinheiro ${ }^{1}$, \\ E.C. Rodrigues-Costa ${ }^{1}$, J.C. Florio ${ }^{1}$, S.F. Lapachinske ${ }^{2}$, R.L.M. Moreau ${ }^{2}$ \\ and J. Palermo-Neto ${ }^{1}$ \\ ${ }^{1}$ Grupo de Pesquisa em Neuroimunomodulação, Faculdade de Medicina Veterinária e Zootecnia, \\ ${ }^{2}$ Análises Clínicas e Toxicológicas, Faculdade de Ciências Farmacêuticas, \\ Universidade de São Paulo, São Paulo, SP, Brasil
}

\begin{abstract}
Anxiolytic and anxiogenic-like behavioral outcomes have been reported for methylenedioxymethamphetamine (MDMA or ecstasy) in rodents. In the present experiment, we attempted to identify behavioral, hormonal and neurochemical outcomes of MDMA treatment to clarify its effects on anxiety-related responses in 2-month-old BALB/c male mice (25-35 g; N = 7-10 mice/ group). The behavioral tests used were open field, elevated plus maze, hole board, and defensive behavior against predator odor. Moreover, we also determined striatal dopamine and dopamine turnover, and serum corticosterone levels. MDMA was injected ip at $0.2,1.0,5.0,8.0,10$, or $20 \mathrm{mg} / \mathrm{kg}$. MDMA at $10 \mathrm{mg} / \mathrm{kg}$ induced the following significant $(P<0.05)$ effects: a) a dose-dependent increase in the distance traveled and in the time spent moving in the open field; b) decreased exploratory activity in the hole board as measured by number of head dips and time spent in head dipping; c) increased number of openarm entries and increased time spent in open-arm exploration in the elevated plus maze; d) increased time spent away from an aversive stimulus and decreased number of risk assessments in an aversive odor chamber; e) increased serum corticosterone levels, and f) increased striatal dopamine level and turnover. Taken together, these data suggest an anxiogenic-like effect of acute MDMA treatment, despite the fact that behavioral anxiety expression was impaired in some of the behavioral tests used as a consequence of the motor stimulating effects of MDMA.
\end{abstract}

Key words: Corticosterone; Open field; Plus maze; Hole board; Predator odor test; Ecstasy

\section{Introduction}

3-4, Methylenedioxymethamphetamine (MDMA or ecstasy) is a synthetic drug used for recreational purposes, mainly by young people. MDMA is as potent neurotransmitter releaser in the central nervous system (CNS) with psychostimulant properties in animals and humans $(1,2)$. In addition, MDMA induces hyperthermia, increases heart rate, activates the hypothalamo-pituitary-adrenal (HPA) axis, and also induces immunological alterations (3-6).

Anxiolytic and anxiogenic-like behavioral outcomes have been extensively studied in MDMA-treated animals using a variety of anxiety models $(7,8)$. However, a noteworthy feature is that contradictory results have been shown depending on the test, dose, gender, and latency after the drug treatment $(7,9)$. Navarro and Maldonado (10) showed in a model of social interaction that the treatment with 5 or $20 \mathrm{mg} / \mathrm{kg}$ MDMA produced an anxiogenic-like response. Maldonado and Navarro (11) also observed contradictory effects of MDMA treatment. In the light-dark box test, they showed an increased latency to move from the lit to the dark compartment, which is consistent with an anxiolyticlike activity of MDMA (11). However, they stated that a social interaction test would be more sensitive to detect an

Correspondence: J. Palermo-Neto, Departamento de Patologia, Faculdade de Medicina Veterinária e Zootecnia, Universidade de São Paulo, Av. Prof. Dr. Orlando M. de Paiva, 87, 05508-270 São Paulo, SP, Brasil. Fax: +55-11-3091-7829. E-mail: jpalermo@usp.br

*These authors contributed equally to this study.

Received November 4, 2010. Accepted April 1, 2011. Available online April 15, 2011. Published May 16, 2011. 
anxiogenic-like response induced by MDMA.

These contradictory results have led some investigators to suggest that high doses of MDMA could be anxiolytic and low doses could be anxiogenic (12) in the elevated plus maze. However, in a more detailed study, Morley and McGregor (8), using cat odor and shock-induced ultrasonic vocalization tests in the elevated plus maze, showed that MDMA administration induced an anxiogenic-like effect, while in the social interaction test MDMA induced an anxiolytic-like effect (8), a test that had already been reported to be anxiogenic in animals treated with the drug $(10,11)$. Therefore, the investigators suggested that MDMA has both anxiogenic- and anxiolytic-like effects depending upon the test and the situation employed (7-9).

Hence, based on these contradictory results found in the literature, our goal was to search for behavioral and neurochemical outcomes of MDMA treatment in mice in an attempt to clarify its effects on anxiety-like responses. Thus, mice were treated with MDMA and first analyzed in the open field and later in the elevated plus maze. Previous results from our group and others have shown that testing animals in an open field or in a hole board immediately before the elevated plus-maze test significantly elevates animal activity within this apparatus, i.e., the total number of open- and closed-arm entries $(13,14)$, with a consequent simplification of analysis of the elevated plus-maze data. We also tested MDMA-treated mice in the hole-board test, since it has been indicated that head-dipping behavior is sensitive to changes in the emotional state of the animal, and the expression of an anxiolytic-like state in animals might be reflected by an increase in frequency and time of head-dipping (15). Predator odor test was also used here to address this issue since fear of a potential predator is known to trigger emotional states such as anxiety. Additionally, hormonal (corticosterone) and neurochemical (dopaminergic activity in the striatum) analyses were also performed in MDMA-treated mice in order to better characterize the behavioral phenomena observed.

\section{Material and Methods}

\section{Animals}

Male BALB/c mice from our own colony, weighing 25-35 $\mathrm{g}$ and about 60 days of age, were used. The animals were housed in controlled-temperature $\left(22-26^{\circ} \mathrm{C}\right)$ and artificially lighted rooms on a 12-h light/12-h dark cycle (lights on at 7:00 am) with free access to rodent chow and water. The experiments were performed in a different room with the same temperature as the animal colony to which the animals were transferred and maintained in their home cages 7 days before the beginning of the experiments. Animals were housed and used in accordance with the guidelines of the Committee on Care and Use of Laboratory Animal Resources of the Faculdade de Medicina Veterinária e Zootecnia, Universidade de São Paulo (Protocol \#1224/2007).

\section{Drugs}

MDMA was extracted from tablets kindly provided by the Brazilian Federal Police Department (Brazil). Upon arrival at the laboratory, the drug was extracted and purified by employing liquid-liquid extraction for the isolation of 3,4-methylenedioxymethamphetamine (MDMA) from ecstasy tablets and afterwards MDMA was crystallized to MDMA hydrochloride (MDMA. $\mathrm{HCl}$ ) as suggested by Lacava et al. (16). The obtained MDMA (99\% homogeneity) was dissolved in $0.9 \% \mathrm{NaCl}$ to concentrations ranging from 0.2 to $20.0 \mathrm{mg} / \mathrm{kg}$. Vehicle $(0.9 \% \mathrm{NaCl})$ was administered alone to the mice of the control group. Solutions were administered intraperitoneally (ip) in a volume of $0.1 \mathrm{~mL} / 10 \mathrm{~g}$.

\section{Behavioral studies}

To minimize the influence of possible circadian changes on the analyzed behaviors, control and experimental animals were alternated for observation, being always analyzed at the same time of day (between 8:00 and 12:00). The experimental devices used were cleaned with $5 \%$ ethanol in water and dried before exchanging each animal in order to obviate possible biasing effects due to odor clues left by previous mice.

\section{Open field}

Briefly, the open-field apparatus consists of a round wooden arena $(40 \mathrm{~cm}$ in diameter, $20-\mathrm{cm}$ high walls) painted black and virtually divided by software (EthoVision System ${ }^{\circledR}$, version 1.9; Noldus Information Technology, USA) into two zones: central (center + median) and peripheral (external + thigmotaxis). The apparatus was elevated $55 \mathrm{~cm}$ above the floor. For the observations, each mouse was individually placed in the center of the apparatus. Parameters measured included distance traveled $(\mathrm{cm})$, time traveling $(\mathrm{s})$, mean velocity $(\mathrm{cm} / \mathrm{s})$, rearing $(\mathrm{N})$, and grooming $(\mathrm{N})$ in each zone. A video camera mounted 100 $\mathrm{cm}$ above the arena was used to collect the data that were analyzed with the EthoVision System ${ }^{\circledR}$ software installed on a compatible computer placed in an adjacent room.

\section{Elevated plus maze}

The elevated plus maze was made of wood, painted black, and had two open arms $(25 \times 5 \mathrm{~cm})$ and two enclosed arms of the same size with $15-\mathrm{cm}$ high walls. The apparatus was elevated $55 \mathrm{~cm}$ above the ground. Each mouse was placed individually in the central square of the elevated plus-maze apparatus and allowed 5 min of free exploration. Each mouse was observed using the same system as described above for the open field (EthoVision System ${ }^{\circledR}$ software). The parameters recorded were: a) number of entries into the open and closed arms, b) time spent exploring the open and closed arms, c) distance traveled, d) time spent moving in the arena, e) rearing $(\mathrm{N})$, f) risk assessment $(\mathrm{N})$, and $\mathrm{g}$ ) total arm entries. The measures that reflect anxiety-like levels in this test are 
the percentage of entries into open arms versus closed arms and the percentage of time spent in the open arms versus closed arms.

\section{Hole board}

The hole-board apparatus was painted black and is similar to that validated for mice by File and Wardill (17). Briefly, it consists of a circular wooden arena $(40 \mathrm{~cm}$ in diameter with $20-\mathrm{cm}$ high walls), with four equally spaced holes ( $3 \mathrm{~cm}$ in diameter) on the floor. Two pellets of food (holes 1 and 3 ) and two plastic toys (holes 2 and 4) were placed underneath the holes. The areas around the holes were virtually marked using the EthoVision System ${ }^{\circledR}$ software and called "exploration zone". The holes are placed in an intermediary zone and are equidistant from each other. The apparatus was elevated $60 \mathrm{~cm}$ from the ground. For the observations, each mouse was individually placed in the center of the apparatus and observed for $5 \mathrm{~min}$ using the system described above (Ethovision System ${ }^{\circledR}$ software). The following parameters were measured and analyzed: distance traveled $(\mathrm{cm})$, mean velocity $(\mathrm{cm} / \mathrm{s})$, number $(\mathrm{N})$, and time (s) of head dippings.

\section{Defensive behavior in response to predator odor}

The apparatus used was constructed as described by Yang et al. (18). Briefly, it consists of a chamber divided into three compartments: a) home chamber, b) tunnel, and c) exposure cage. The home chamber was a $7 \times 7 \times 12$ $\mathrm{cm}$ box made of three black sides and one clear side to facilitate videotaping. The home chamber was connected to the exposure cage by a clear tube tunnel $(4.4 \mathrm{~cm}$ in diameter, $13 \mathrm{~cm}$ in length, and elevated $1.5 \mathrm{~cm}$ from the floor of the two chambers). The exposure cage was a 46 $\times 24 \times 21 \mathrm{~cm}$ clear polycarbonate cage covered with a metal lid and divided into two equal-sized compartments by a wire mesh screen. In our protocol, a piece of fabric on which a cat had slept for 30 days was placed inside the right side compartment of the exposure cage to act as a predator stimulus of cat odor. Entries in the contact zone were considered when mice stood near the wire mesh screen. The animals were recorded using a horizontally mounted video camera. Prior to the beginning of each trial, the home cage bedding of each subject was placed on the floor of the apparatus. The testing procedure consisted of two phases: a) Habituation: each animal was placed on the left side of the exposure cage in the absence of cat odor. Each animal was allowed to explore for $10 \mathrm{~min}$ for 3 consecutive days; b) test: each animal was placed on the left side of the exposure cage in the presence of cat odor, which was placed in the right side compartment, and animals were recorded for $10 \mathrm{~min}$. The following parameters were analyzed: time in home chamber (s), time in tunnel (s), entries into the exposure cage $(N)$, entries into the contact zone (near the wire mesh screen; $N$ ), risk assessment $(\mathrm{N})$, and grooming $(\mathrm{N})$.

\section{Neurochemical measurements}

Animals were euthanized by decapitation and the brains were immediately removed and dissected, with the striatum being excised as quickly as possible (over a period of no more than $3 \mathrm{~min}$ ), then weighed and frozen on dry ice. Samples were homogenized by sonication in 0.1 $\mathrm{M}$ perchloric acid containing $1.1 \mathrm{mM}$ sodium metabisulfite and $0.54 \mathrm{mM}$ disodium EDTA, and centrifuged for $30 \mathrm{~min}$ at $11,200 \mathrm{~g}$. The supernatants were stored frozen at $-80^{\circ} \mathrm{C}$ until analysis. Dopamine (DA) and its metabolites homovanillic acid (HVA) and dihydroxyphenylacetic acid (DOPAC) were measured using a high performance liquid chromatography system (model 6A, Shimadzu, Japan) with an electrochemical detector (model 6A, Shimadzu) as described in detail elsewhere (19). Briefly, samples $(20 \mu \mathrm{L})$ were loaded into a sample injector and the mobile phase was delivered at a constant rate of $0.5 \mathrm{~mL} / \mathrm{min}$ through a $\mathrm{C} 18$ analytical column (Shimpak, ODS, Japan) placed inside a column heater $\left(35^{\circ} \mathrm{C}\right)$. The mobile phase, $\mathrm{pH} 2.9$, consisted of 0.02 $\mathrm{M}$ disodium phosphate, $0.02 \mathrm{M}$ citrate, $0.11 \mathrm{mM}$ disodium EDTA, $2.75 \mathrm{mM}$ heptanesulfonic acid, and $10 \%$ methanol. The signal from the detector was recorded with an integrator (Chromatopac, Shimadzu) and the run time for each sample was 25 min. Inter- and intra-assay coefficients of variation were smaller than $15 \%$ and the recovery rates higher than $80 \%$ for both substances. The concentrations of DA, HVA and DOPAC are reported as $\mathrm{ng} / \mathrm{g}$ tissue.

\section{Serum corticosterone determination}

Corticosterone was determined in serum using commercially available kits (Coat-a-Count, DPC, USA). This procedure is based on a solid-phase radioimmunoassay in which ${ }^{125}$-labeled corticosterone competes for antibody sites for a fixed time with the corticosterone present in the murine sample. Serum samples were assayed directly without extraction or purification. To decrease the variability of serum corticosterone levels, the mice were handled daily for a period of 7 days for habituation to the experimental conditions to be used later for euthanasia and blood collection. Animals were euthanized by decapitation and in order to minimize the reported circadian variations of serum glucocorticoid levels, control and experimental animals were intermixed for euthanasia and the blood was taken at the same time of day, i.e., between 8.00 and $9.00 \mathrm{am}$, 30,60 , and 120 min after the administration of MDMA or $0.9 \% \mathrm{NaCl}$

\section{Experimental design}

Six experiments were performed in accordance with Good Laboratory Practices (GLP) standards and quality assurance methods: a) mice were randomly treated with $\operatorname{MDMA}(0.2,1.0,5.0,8.0,10$, or $20 \mathrm{mg} / \mathrm{kg})$ or $0.9 \% \mathrm{NaCl}$. After $60 \mathrm{~min}$, each mouse was placed in the center of the open field and allowed to explore it for $5 \mathrm{~min}$; b) mice were randomly treated with MDMA (5.0 or $10 \mathrm{mg} / \mathrm{kg}$ ) or $0.9 \%$ 
$\mathrm{NaCl}$. After 60 min, each mouse was placed in the center of the hole board and allowed to explore it for $5 \mathrm{~min}$; c) mice received $10 \mathrm{mg} / \mathrm{kg}$ MDMA or $0.9 \% \mathrm{NaCl}$ in a random order and after 60 min were placed in the center of the open field and allowed to explore it for $5 \mathrm{~min}$. The animals previously observed in the open field were then immediately tested individually in the elevated plus maze for an additional 5 min; d) mice were randomly divided into two groups and, after habituation to the predator odor chamber, they received $10 \mathrm{mg} / \mathrm{kg}$ MDMA or $0.9 \% \mathrm{NaCl}$. After $60 \mathrm{~min}$, each mouse was placed on the left side of the exposure cage and allowed to explore the compartments for $10 \mathrm{~min}$; e) mice were randomly treated with $10 \mathrm{mg} / \mathrm{kg}$ MDMA or $0.9 \% \mathrm{NaCl}$. After 60 min, the striatum was harvested to measure dopamine and its HVA and DOPAC; f) mice received $10 \mathrm{mg} / \mathrm{kg}$ MDMA or $0.9 \% \mathrm{NaCl}$ and 30,60 , and $120 \mathrm{~min}$ later blood samples were collected to measure serum corticosterone levels. Seven to 10 mice/group were used in each experiment.

A 60-min interval between injection and test exposure was chosen on the basis of published data $(3,16)$. We have shown that plasma MDMAconcentration already reaches a peak after $60 \mathrm{~min}$ (16) and therefore it seems reasonable to suggest that this is the most appropriate interval to analyze MDMA behavioral outcomes.

\section{Statistical analysis}

GraphPad Prism 5.0 software (GraphPad Softwares Inc., USA) was employed throughout for statistical analysis. Parametric data were analyzed by the unpaired Student $t$-test or one-way ANOVA followed by Dunnett's multiple comparison test. The Mann-Whitney U-test or Kruskal-Wallis test (KW) followed by Dunn's multiple comparison tests was used to analyze non-parametric data. Moreover, analysis of covariance (ANCOVA) was performed to determine the independence of changes observed in the elevated plus maze. In all experiments, $\mathrm{P}<0.05$ was considered to be significant. Data are reported as means \pm SEM.

\section{Results}

\section{MDMA increases locomotor activity in the open field}

Our first goal was to construct a doseresponse curve for the effects of MDMA in the open field. We observed that treatment with $5.0,8.0,10$, and $20 \mathrm{mg} / \mathrm{kg}$ MDMA increased the distance traveled in the total arena $(F(6,48)=72.61$; $P<0.0001)$ and peripheral zone $(8.0,10$, and $20 \mathrm{mg} / \mathrm{kg}$; KW (42.10); $P<0.0001$; Figure 1A). We also observed that MDMA at $1.0,5.0$, and $20 \mathrm{mg} / \mathrm{kg}$ increased the distance traveled in the central zone $(\mathrm{KW}(27.66) ; \mathrm{P}=0.0001)$ of the open field (Figure 1A). Similarly, we observed that MDMA at $5.0,8.0,10$, and $20 \mathrm{mg} / \mathrm{kg}$ increased the time spent in the total arena (KW (41.87); $\mathrm{P}<0.0001)$ and in the peripheral zone (KW (42.00); P <0.0001; Figure 1B); we also observed that MDMA at 1.0, 5.0, 10, and $20 \mathrm{mg} / \mathrm{kg}$ increased the time spent in the central zone $(F(6,48)=3.564 ; \mathrm{P}<0.01)$ of the

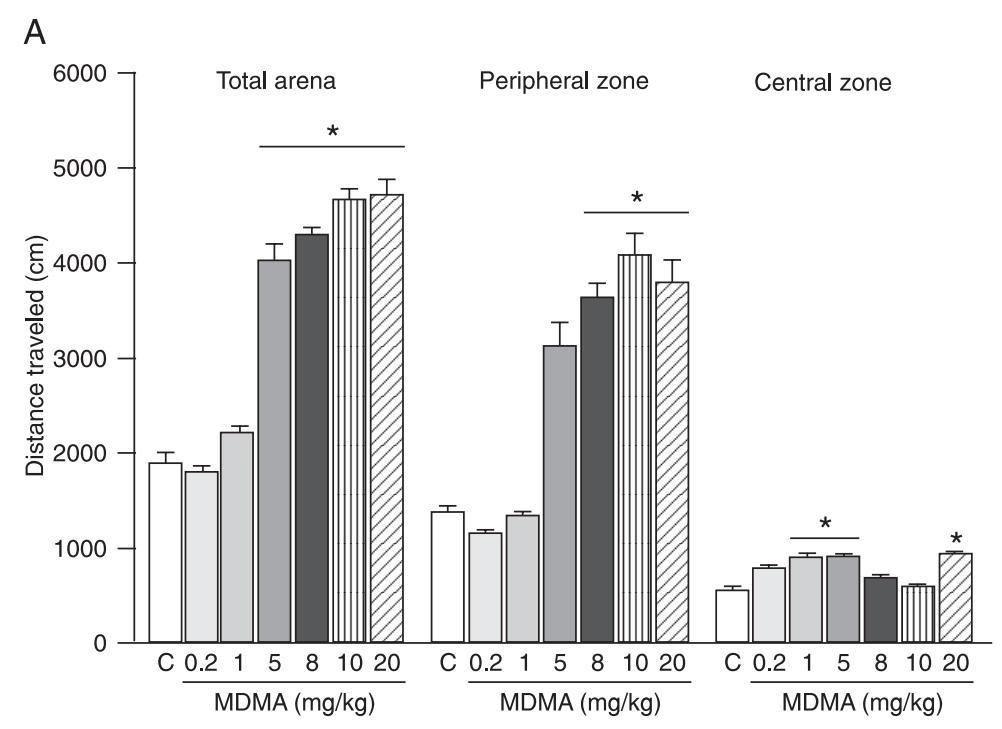

B

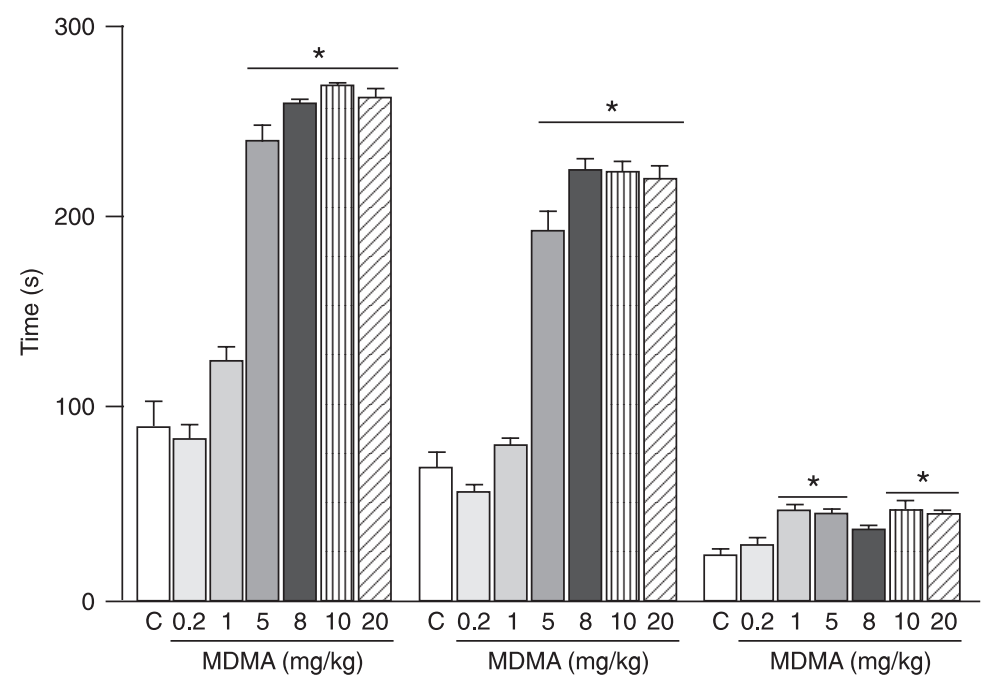

Figure 1. Behavioral effects of 3,4-methylenedioxymethamphetamine (MDMA) on BALB/c male mice in the open-field test. $A$, Distance traveled and $B$, time spent in movement during the $5 \mathrm{~min}$ of the test (total arena, peripheral and central zones). Data are reported as means \pm SEM for 7-8 animals/group. ${ }^{*} P<0.05$ compared to control (one-way ANOVA followed by Dunnett's multiple comparison test or Kruskal-Wallis test followed by Dunn's multiple comparison test). 
open field (Figure 1B). Moreover, we observed an increase in the mean velocity (KW (43.07); $\mathrm{P}<0.0001)$ and a decrease in frequency of both rearing (KW (41.24); $\mathrm{P}<0.0001)$ and grooming $(F(6,48)=15.91 ; P<0.0001)$ after treatment with MDMA at 5.0, 8.0, 10, and $20 \mathrm{mg} / \mathrm{kg}$ (Table 1).

\section{MDMA increases locomotor activity and decreases exploratory behavior in the hole board}

Since there were no statistically significant differences among MDMA doses $(5.0,8.0,10$, and $20 \mathrm{mg} / \mathrm{kg}$ ) in the open-field test (see Figure $1 \mathrm{~A}$ and $\mathrm{B}$ ), we performed the hole-board test using only 5.0 and $10 \mathrm{mg} / \mathrm{kg}$ MDMA-treated mice. We observed that MDMA-treated mice (5.0 and 10 $\mathrm{mg} / \mathrm{kg}$ ) presented an increase in both distance traveled $(\mathrm{F}$ $(2,27)=63.02 ; \mathrm{P}<0.0001)$ and mean velocity $(\mathrm{F}(2,27)$ $=32.90 ; \mathrm{P}<0.0001 ;$ Figure $2 \mathrm{~A}$ and $\mathrm{B})$. Additionally, we observed that MDMA-treated mice $(5.0$ and $10 \mathrm{mg} / \mathrm{kg}$ ) presented a decreased number $(F(2,27)=70.28 ; P<0.0001)$ and time $(F(2,27)=51.94 ; P<0.0001)$ of head-dipping (Figure 2C and D).

Table 1. Effects of 3,4-methylenedioxymethamphetamine (MDMA, $10 \mathrm{mg} / \mathrm{kg}$ ) on BALB/c male mice in the open field 60 min after treatment.

\begin{tabular}{|c|c|c|c|c|c|c|c|}
\hline Open-field parameters & Control & $\begin{array}{c}\text { MDMA } \\
(0.2 \mathrm{mg} / \mathrm{kg})\end{array}$ & $\begin{array}{c}\text { MDMA } \\
(1.0 \mathrm{mg} / \mathrm{kg})\end{array}$ & $\begin{array}{c}\text { MDMA } \\
(5.0 \mathrm{mg} / \mathrm{kg})\end{array}$ & $\begin{array}{c}\text { MDMA } \\
(8.0 \mathrm{mg} / \mathrm{kg})\end{array}$ & $\begin{array}{c}\text { MDMA } \\
(10 \mathrm{mg} / \mathrm{kg})\end{array}$ & $\begin{array}{c}\text { MDMA } \\
(20 \mathrm{mg} / \mathrm{kg})\end{array}$ \\
\hline Mean velocity $(\mathrm{cm} / \mathrm{s})$ & $6.198 \pm 0.51$ & $5.881 \pm 0.35$ & $7.270 \pm 0.34$ & $12.65 \pm 0.89^{*}$ & $13.91 \pm 0.46^{*}$ & $16.14 \pm 0.74^{*}$ & $15.02 \pm 0.94^{*}$ \\
\hline Rearing $(\mathrm{N})$ & $27.13 \pm 3.86$ & $24.29 \pm 2.45$ & $30.38 \pm 3.05$ & $6.500 \pm 1.31^{*}$ & $5.625 \pm 1.99^{*}$ & $2.500 \pm 0.63^{*}$ & $4.500 \pm 0.94^{*}$ \\
\hline Grooming (N) & $10.88 \pm 1.89$ & $9.000 \pm 1.79$ & $7.375 \pm 1.76$ & $1.000 \pm 0.60^{*}$ & $0.000 \pm 0.00^{*}$ & $0.000 \pm 0.00^{*}$ & $0.625 \pm 0.32^{*}$ \\
\hline
\end{tabular}

Data are reported as means \pm SEM for 7-8 animals/group. * $\mathrm{P}<0.05$ compared to control (one-way ANOVA followed by Dunnett's multiple comparison test or Kruskal-Wallis test followed by Dunn's multiple comparison test).
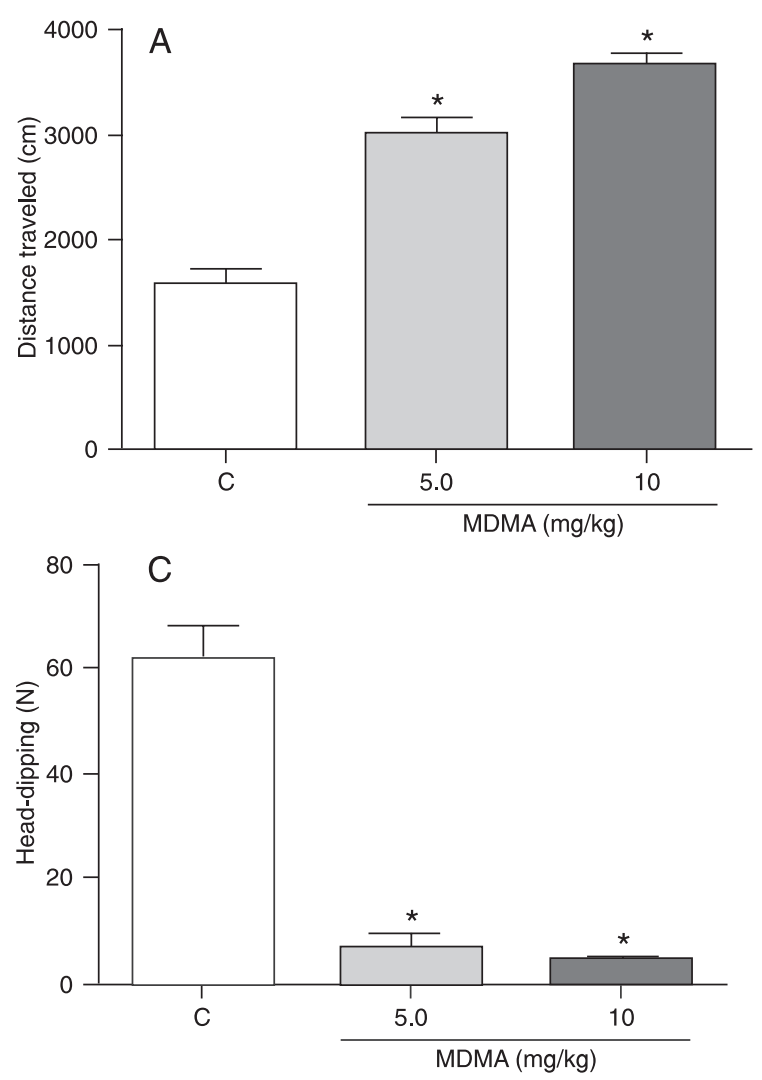
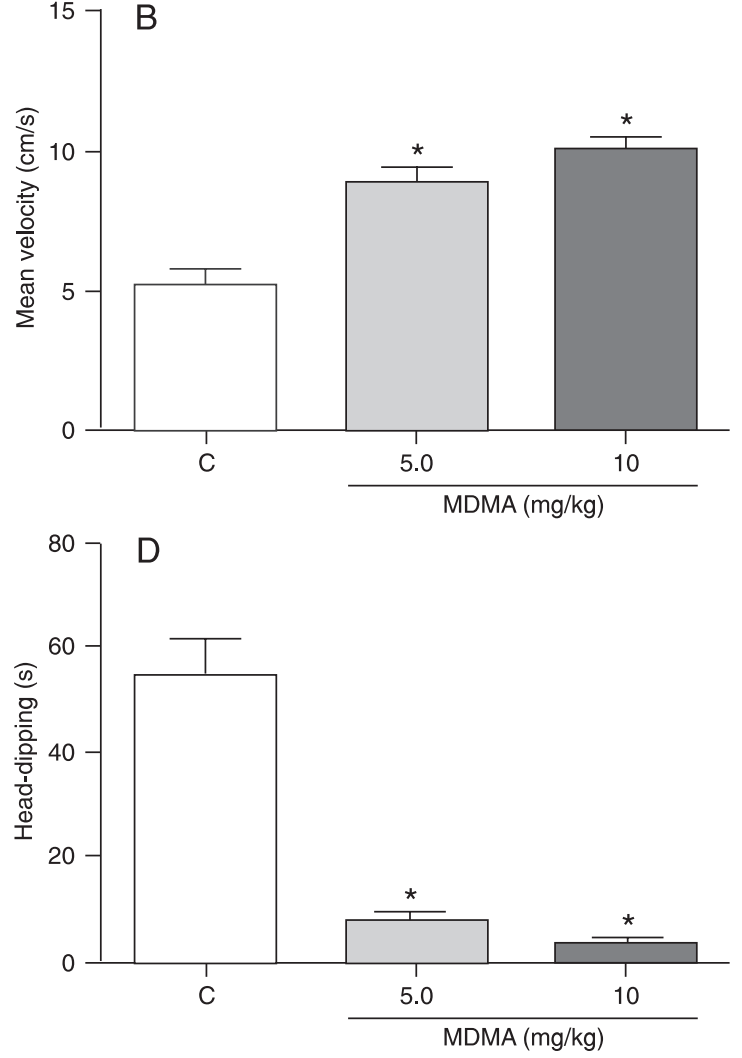

Figure 2. Behavioral effects of 3,4-methylenedioxymethamphetamine (MDMA) on BALB/c male mice in the hole-board test. $A$, Distance traveled $(\mathrm{cm}) ; B$, mean velocity $(\mathrm{cm} / \mathrm{s}) ; C$, number of head dips; $D$, time spent during head-dipping. Data are reported as means \pm SEM for 10 animals/group. ${ }^{*} \mathrm{P}<0.05$ compared to control group (one-way ANOVA followed by Dunnett's multiple comparison test). 

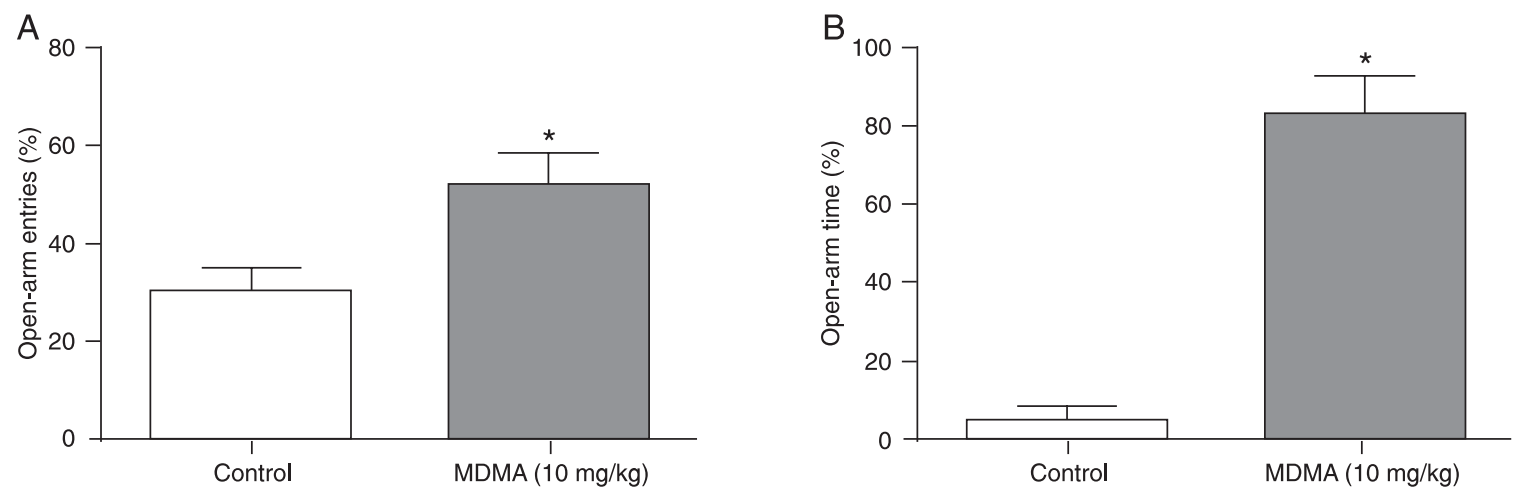

Figure 3. Behavioral effects of 3,4-methylenedioxymethamphetamine (MDMA) on BALB/c male mice in the elevated plusmaze test. $A$, Percent of open-arm entries and $B$, percent of open-arm time during the $5 \mathrm{~min}$ of the test. Data are reported as means \pm SEM for 9-10 animals/group. ${ }^{*} \mathrm{P}<0.05$ compared to control (Student $t$-test or Mann-Whitney U-test).

\section{MDMA induces anxiolytic-like behavior in the elevated plus maze}

Since we did not observe any difference between 5.0 and $10 \mathrm{mg} / \mathrm{kg}$ MDMA in the hole-board test (see Figure 2), we decided to use MDMA only at $10 \mathrm{mg} / \mathrm{kg}$. Similarly to the results reported above, in the open field, mice treated with $10 \mathrm{mg} / \mathrm{kg}$ MDMA presented an increase in the distance traveled in the total arena $(t(17)=8.931 ; \mathrm{P}<0.0001)$, as well as in the peripheral $(t(17)=5.612 ; \mathrm{P}<0.0001)$ and central $(U(3.0)$; $\mathrm{P}<0.001)$ zones. We also observed that MDMA treatment increased the time spent in the total arena $(U(0.0)$; $\mathrm{P}<0.0001)$, and in the peripheral $(t(17)=8.049 ; \mathrm{P}<$ $0.0001)$ and central $(t(17)=4.521 ; \mathrm{P}<0.001)$ zones. Moreover, we observed an increase in the mean velocity $(t(17)=8.928 ; \mathrm{P}<0.0001)$ and a decrease in the frequency of both rearing $(U(1.0) ; P<0.001)$ and grooming $(U(5.5) ; P<0.001)$.

In the elevated plus maze, we observed that MDMAtreated mice presented both increased entries (\%) $(t$ $(17)=2.510 ; \mathrm{P}<0.05)$ and time spent $(\%)(U(2.0) ; \mathrm{P}<$ 0.001 ) in the open arms (Figure $3 A$ and $B$, respectively). As expected, the contrary was observed in the closedarm entries and time $(t(17)=2.510, \mathrm{P}<0.05 ; U(2.0)$; $\mathrm{P}<0.001$; Table 2). Furthermore, MDMA increased both distance traveled $(t(17)=5.101 ; \mathrm{P}<0.0001)$ and time spent moving $(t(17)=3.743 ; \mathrm{P}<0.001)$ in the total plusmaze arena (Table 2). We also observed a decrease in the frequency of rearing $(t(17)=4.098 ; \mathrm{P}<0.001)$, risk assessment $(U(0.5) ; P=0.001)$ and total arm entries $(t(17)=4.284 ; \mathrm{P}<0.001$; Table 2).

ANCOVA showed that time of exploration (\%) in the open arms was not influenced by the number of entries (\%) in the closed arms, which means that the differences found were caused only by MDMA treatment $(F(1,16)=0.97 ; P=0.34)$.
Table 2. Effects of 3,4-methylenedioxymethamphetamine (MDMA, $10 \mathrm{mg} / \mathrm{kg}$ ) on BALB/c male mice in the elevated plus maze $60 \mathrm{~min}$ after treatment.

\begin{tabular}{lcc}
\hline $\begin{array}{l}\text { Elevated plus-maze } \\
\text { parameters }\end{array}$ & Control & $\begin{array}{c}\text { MDMA } \\
(10 \mathrm{mg} / \mathrm{kg})\end{array}$ \\
\hline Distance traveled $(\mathrm{cm})$ & $1282 \pm 63.17$ & $1806 \pm 82.41^{*}$ \\
Time (s) & $44.37 \pm 5.03$ & $85.42 \pm 10.14^{*}$ \\
Rearing (N) & $22.40 \pm 1.26$ & $11.67 \pm 2.39^{*}$ \\
Risk assessment (N) & $34.63 \pm 10.29$ & $18.50 \pm 2.56^{*}$ \\
Arm entries (N) & $38.60 \pm 2.50$ & $16.11 \pm 4.80^{*}$ \\
Closed arms entries (\%) & $69.70 \pm 14.56$ & $48.99 \pm 21.14^{*}$ \\
Closed arms time (\%) & $94.84 \pm 9.02$ & $17.50 \pm 29.78^{*}$ \\
\hline
\end{tabular}

Data are reported as means \pm SEM for 9-10 animals/group. ${ }^{*} \mathrm{P}<0.05$ compared to control (Student $t$-test or Mann-Whitney U-test).

Table 3. Effects of 3,4-methylenedioxymethamphetamine (MDMA, $10 \mathrm{mg} / \mathrm{kg}$ ) on defensive behavior on BALB/c male mice in response to cat odor $60 \mathrm{~min}$ after treatment.

\begin{tabular}{lcc}
\hline $\begin{array}{l}\text { Defensive behavior } \\
\text { parameters }\end{array}$ & Control & $\begin{array}{c}\text { MDMA } \\
(10 \mathrm{mg} / \mathrm{kg})\end{array}$ \\
\hline Time in home chamber (s) & $369.4 \pm 48.0$ & $519.6 \pm 36.6^{*}$ \\
Time in tunnel (s) & $63.8 \pm 12.5$ & $25.4 \pm 15.6^{*}$ \\
Entries into exposure cage (N) & $7.2 \pm 2.3$ & $2.6 \pm 1.9^{*}$ \\
Entries into contact zone (N) & $3.7 \pm 0.7$ & $1.5 \pm 0.8^{*}$ \\
Grooming frequency (N) & $4.1 \pm 2.1$ & $4.5 \pm 2.0$ \\
Risk assessment $(\mathrm{N})$ & $3.7 \pm 0.9$ & $2.0 \pm 1.1^{*}$ \\
\hline
\end{tabular}

Data are reported as means \pm SEM for 10 animals/group. ${ }^{*} \mathrm{P}<$ 0.05 compared to control (Student $t$-test). 
A

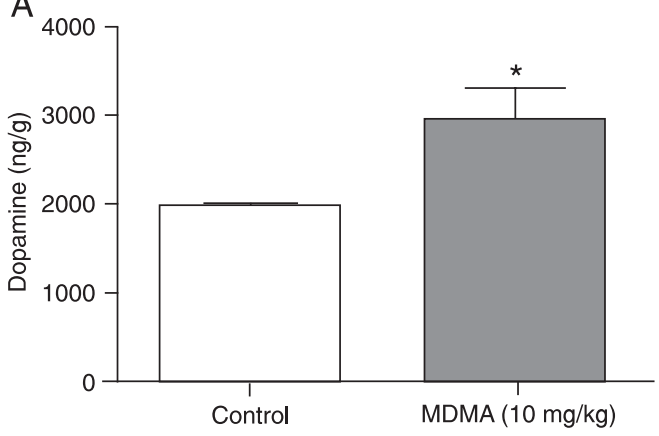

C

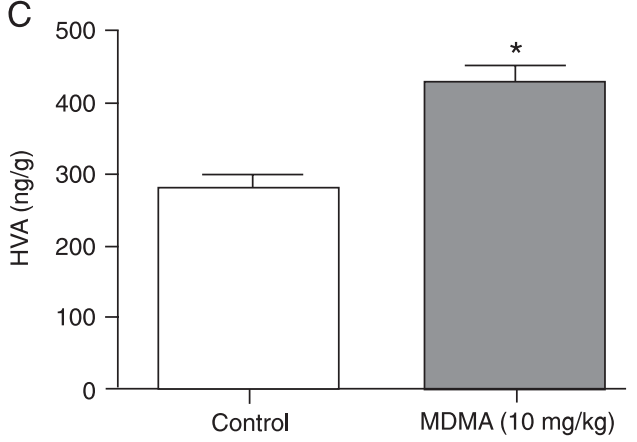

B

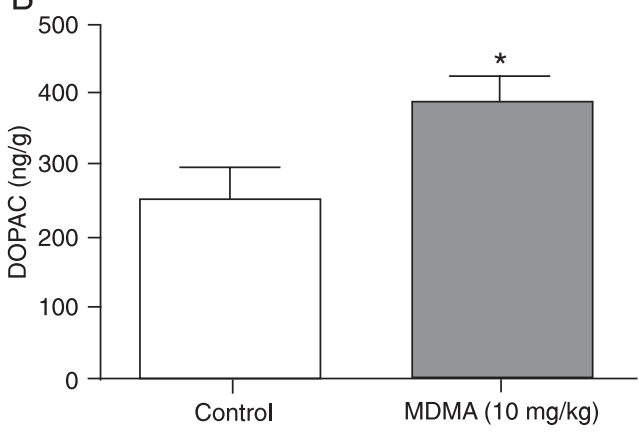

D

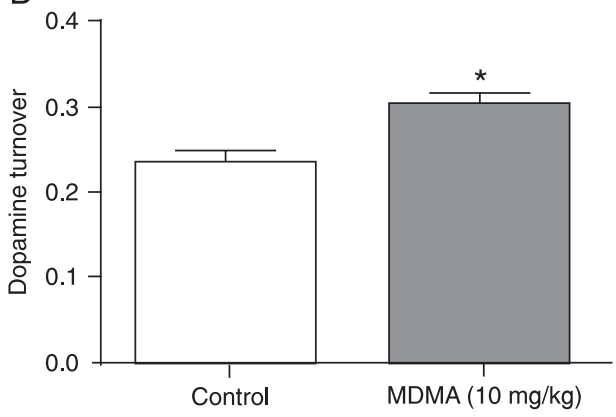

Figure 4. Effects of 3,4-methylenedioxymethamphetamine (MDMA) on the striatal content and turnover of dopamine and its metabolites on BALB/c male mice. $A$, Dopamine; $B$, dihydroxyphenylacetic acid (DOPAC); $C$, homovanillic acid (HVA); $D$, dopamine turnover (DOPAC+HVA/DA). Data are reported as means $\pm \mathrm{SEM}$ for $9-10$ animals/group. ${ }^{*} \mathrm{P}<0.05$ compared to control (Student $t$-test or Mann-Whitney U-test).

\section{MDMA increases defensive behavior in the presence of cat odor}

Finally, we decided to perform a defensive behavior test in order to compare the data obtained with the behavioral results reported above. We observed that MDMA increased the time spent in the home chamber $(t(18)=7.843$; $\mathrm{P}<$ $0.001)$ and decreased the time spent in the tunnel $(t(18)$ $=6.063 ; \mathrm{P}<0.001)$. MDMA also decreased the number of entries into the exposure cage $(t(18)=4.951 ; \mathrm{P}<0.001)$ and into the contact zone $(t(18)=4.610 ; \mathrm{P}<0.001)$, and the frequency of risk assessments was reduced as well $(t(18)$ $=3.791 ; \mathrm{P}<0.001 ;$ Table 3 ). Grooming was not changed by MDMA treatment.

\section{MDMA increases dopamine turnover in the striatum}

Based on the results of the reported behavioral tests, we thought it would be interesting to analyze the effects of a similar protocol of MDMA treatment on dopamine level and turnover in the striatum. We showed that MDMA increased striatal dopamine $(U(17) ; \mathrm{P}<0.05)$, DOPAC $(t$ $(17)=2.253 ; \mathrm{P}<0.05)$ and $\mathrm{HVA}(t(17)=4.906 ; \mathrm{P}<0.0001)$ contents (Figure $4 A, B$ and $C$, respectively). Furthermore, we observed that dopamine turnover (DOPAC+HVA/DA) was higher in MDMA-treated mice than in control mice $(t(17)=2.543 ; \mathrm{P}<0.05$; Figure 4D).

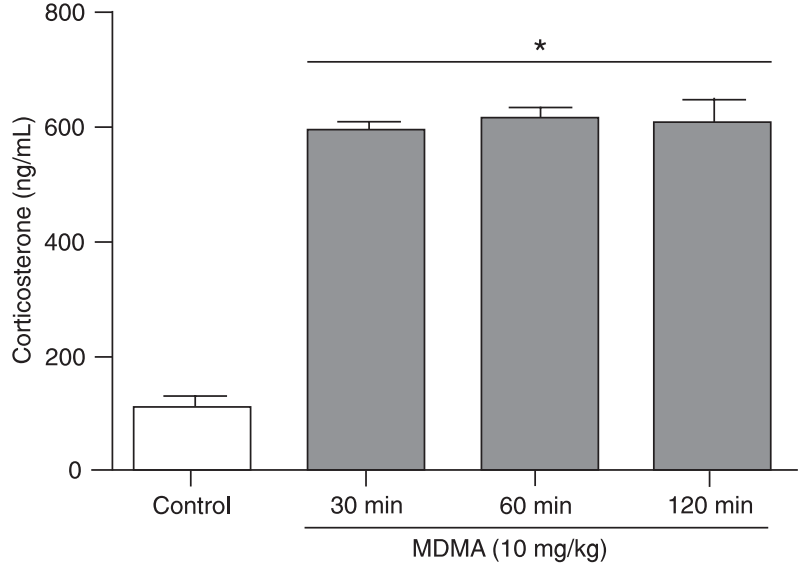

Figure 5. Effects of 3,4-methylenedioxymethamphetamine (MDMA) on corticosterone serum levels 30,60, and 120 min after administration to BALB/c male mice. Data are reported as means \pm SEM for 10 animals/group. * $\mathrm{P}<0.05$ compared to control (oneway ANOVA followed by Dunnett's multiple comparison test).

\section{MDMA increases serum corticosterone levels}

Finally, we analyzed the level of corticosterone in serum after 30,60 , and $120 \mathrm{~min}$ of MDMA (10 mg/kg) treatment. We showed that MDMA increased serum corticosterone 
levels (KW (38.90); $\mathrm{P}<0.0001)$ approximately 6 -fold at all times analyzed (Figure 5).

\section{Discussion}

We reported here the differential behavioral outcomes for MDMA administration in mice. We showed that the magnitude and extent of the behavioral outcome observed depended on the behavioral test used. Thus, MDMA induced a dose-dependent increase in the distance traveled and in the time spent moving in the open field. Furthermore, MDMA decreased the exploratory activity in the hole board, as measured by number of head dippings and time spent in head dipping. MDMA also increased the number of openarm entries and time spent in open-arm exploration in a plus-maze apparatus. Finally, using a predator odor test device, we showed that MDMA increased time spent away from the aversive stimulus and decreased the number of risk assessments in the tunnel of the apparatus.

Anxiety level is operationally inferred as suggested elsewhere (20), i.e., as a response to a situation in which behavior is influenced by two opposing motivational forces (e.g., a natural curiosity to explore unexplored or novel areas versus an aversion to open areas). Thus, increments in number of entries or in the time spent by rodents in the plus-maze open arms commonly indicate the presence of decreased levels of anxiety $(20,21)$. Anxiogenic drugs are reported to increase the time spent in the peripheral zone of the open field, decreasing, at the same time, the permanence of the animal in the central zones $(22,23)$. Conversely, anxiolytic drugs have been shown to reduce exploration of the peripheral open-field zones (24). Here, we showed that MDMA-treated mice traveled an increased distance $(\mathrm{cm})$ in the peripheral and central open-field zones as well as in the hole-board apparatus; we also showed an increase in time spent and number of entries into plusmaze open arms. Thus, at first glance these data suggest an anxiolytic-like profile for MDMA in mice, in agreement with data reported elsewhere (8).

MDMA, like other amphetamines, is known to increase nigrostriatal DA activity (25) and consequently increases the distance traveled, as reported here. The existence of a positive correlation between distance traveled and nigrostriatal dopaminergic activity is of common knowledge. Dawson et al. (26) showed that rats treated with d-amphetamine presented an increase in number of entries into the open arms of the plus maze. However, the drug concomitantly increased the total distance traveled and the mean velocity of the animals in the closed arms of the plus maze. These data led these investigators to suggest that psychomotor-stimulating compounds such as amphetamines might have an anxiolytic-like profile in the elevated plus maze. According to Lister (21), alteration of animal behavior in the plus maze, which somehow was interpreted to correspond to decreased levels of anxiety, might have been confounded by alterations in locomotor activity. A similar interpretation seems to be valid for the behavioral data reported here in the open field, hole board and plus maze, indicating that MDMA altered locomotor activity rather than affecting the levels of anxiety. Indeed, MDMA increased all locomotion parameters measured in the three apparatuses, in agreement with data reported by Fletcher et al. (27). Therefore, we believe that the data obtained here for MDMA treatment in the predator odor behavioral test and neurochemical/hormonal analysis might shed some light on the discussion regarding anxiogenic versus anxiolytic-like responses.

Defensive behaviors are innate and unconditioned reactions of an organism toward actual or potential threats (18). Anxiety, fear and stress are behavioral outcomes of the activation of CNS defensive systems (28). Rodents become defensive in the presence of a predator (28), of predator odor (18) and also when placed in strange places (29). The data obtained here using the predator odor test apparatus showed that MDMA treatment increased time spent in the home chamber. Moreover, MDMA decreased the number of risk assessments in the tunnel and in the exposure chamber. These data strongly suggest that MDMA increased the animals' level of anxiety. Indeed, similar behavioral results were reported in studies using a similar apparatus after different stressors (30) or feareliciting stimuli $(18,29)$. This hypothesis is consistent with results reported using the social interaction test $(10,31)$.

Stressors are known to increase serum corticosterone levels $(3,14)$ and catecholaminergic activity in the CNS $(32,33)$. An increase in serum corticosterone level as well as in striatal dopamine level and turnover was shown in the present study after MDMA treatment. Hence, it seems reasonable to suggest that MDMA has an anxiogenic-like effect on mice. Indeed, we have already reported that MDMA $(10 \mathrm{mg} / \mathrm{kg}$ ) increased hypothalamic noradrenergic activity (3). Limbic brain areas, such as hypothalamus, amygdala and hippocampus, exhibit rapid and large increases in noradrenaline turnover in anxiogenic situations $(32,34)$. The mesolimbic dopaminergic system has already been related to anxiety-like responses (35). Correlation studies between tyrosine hydroxylase activity, dopamine level and anxiety-like responses have suggested that decreasing tyrosine hydroxylase activity, which in turn leads to decreased dopamine levels, is negatively related to the levels of anxiety measured in a plus-maze apparatus $(36,37)$. Furthermore, increases in serum corticosterone levels were reported after application of physical, psychological and chemical stressors $(3,14,38,39)$.

Taken together, the present data suggest an anxiogenic-like effect of acute MDMA treatment despite the fact that the expression of behavioral anxiety was impaired in some of the behavioral tests used, most probably as a consequence of the locomotor action of MDMA. Research on behavioral, endocrine and neurochemical effects of 
drugs on anxiety, stress and fear in laboratory animals are implicitly motivated by an expectation that such results may be useful and extrapolated to humans. Thus, the present data suggest that MDMA use might increase the levels of anxiety, stress and fear in humans. Furthermore, it should not be forgotten that these feelings are common components of aggressive responses in labora-

\section{References}

1. Liechti ME, Vollenweider FX. Which neuroreceptors mediate the subjective effects of MDMA in humans? A summary of mechanistic studies. Hum Psychopharmacol 2001; 16: 589598.

2. De La Torre R, Farre M. Neurotoxicity of MDMA (ecstasy): the limitations of scaling from animals to humans. Trends Pharmacol Sci 2004; 25: 505-508.

3. de Paula V, Ribeiro A, Pinheiro ML, Sakai M, Lacava MC, Lapachinske SF, et al. Methylenedioxymethamphetamine (Ecstasy) decreases neutrophil activity and alters leukocyte distribution in bone marrow, spleen and blood. Neuroimmunomodulation 2009; 16: 191-200.

4. Connor TJ. Methylenedioxymethamphetamine (MDMA, 'Ecstasy'): a stressor on the immune system. Immunology 2004; 111: 357-367.

5. Pacifici R, Zuccaro P, Farre M, Pichini S, Di Carlo S, Roset $\mathrm{PN}$, et al. Effects of repeated doses of MDMA ("ecstasy") on cell-mediated immune response in humans. Life Sci 2001; 69: 2931-2941.

6. Boyle NT, Connor TJ. MDMA ("Ecstasy") suppresses the innate IFN-gamma response in vivo: a critical role for the anti-inflammatory cytokine IL-10. Eur J Pharmacol 2007; 572: 228-238.

7. Palenicek T, Votava M, Bubenikova V, Horacek J. Increased sensitivity to the acute effects of MDMA ("ecstasy") in female rats. Physiol Behav 2005; 86: 546-553.

8. Morley KC, McGregor IS. (+/-)-3,4-methylenedioxymethamphetamine (MDMA, 'Ecstasy') increases social interaction in rats. Eur J Pharmacol 2000; 408: 41-49.

9. Mechan AO, Moran PM, Elliott M, Young AJ, Joseph $M H$, Green R. A study of the effect of a single neurotoxic dose of 3,4-methylenedioxymethamphetamine (MDMA; "ecstasy") on the subsequent long-term behaviour of rats in the plus maze and open field. Psychopharmacology 2002; 159: 167175.

10. Navarro JF, Maldonado E. Behavioral profile of 3,4-methylenedioxymethamphetamine (MDMA) in agonistic encounters between male mice. Prog Neuropsychopharmacol Biol Psychiatry 1999; 23: 327-334.

11. Maldonado E, Navarro JF. Effects of 3,4-methylenedioxymethamphetamine (MDMA) on anxiety in mice tested in the light-dark box. Prog Neuropsychopharmacol Biol Psychiatry 2000; 24: 463-472.

12. Lin HQ, Burden PM, Christie MJ, Johnston GA. The anxiogenic-like and anxiolytic-like effects of MDMA on mice in the elevated plus-maze: a comparison with amphetamine. Pharmacol Biochem Behav 1999; 62: 403-408.

13. Ribeiro A, Ferraz-de-Paula V, Pinheiro ML, Palermo-Neto $J$. Dose-response effects of systemic anandamide adminis- tory animals, wild-type animals and humans (40).

\section{Acknowledgments}

The authors wish to thank FAPESP (\#05/52288-1 and \#04/14128-0) and CNPq (\#477621/2004-0, \#472083/20070 and \#301177/2007-4) for financial support.

tration in mice sequentially submitted to the open field and elevated plus-maze tests. Braz J Med Biol Res 2009; 42: 556-560.

14. Palermo-Neto J, de Oliveira MC, Robespierre de Souza W. Effects of physical and psychological stressors on behavior, macrophage activity, and Ehrlich tumor growth. Brain Behav Immun 2003; 17: 43-54.

15. Takeda H, Tsuji M, Matsumiya T. Changes in head-dipping behavior in the hole-board test reflect the anxiogenic and/or anxiolytic state in mice. Eur J Pharmacol 1998; 350: 21-29.

16. Lacava M, Ferraz-de-Paula V, Lapachinske SF, PalermoNeto J, Moreau RLM. Simultaneous determination of methylenodioxymethamphetamine (MDMA) and methylenodioxyamphetamine (MDA) in plasma by gas chromatography with nitrogen-phosphorus detection (GC-NPD) and in vitro effects on the neutrophil activity of mice. III Encuentro Regional de Toxicologia Forense. Bogotá: TIAFT; 2007. p 97-104.

17. File SE, Wardill AG. Validity of head-dipping as a measure of exploration in a modified hole-board. Psychopharmacologia 1975; 44: 53-59.

18. Yang M, Augustsson $\mathrm{H}$, Markham CM, Hubbard DT, Webster $D$, Wall PM, et al. The rat exposure test: a model of mouse defensive behaviors. Physiol Behav 2004; 81: 465-473.

19. Felicio LF, Florio JC, Sider LH, Cruz-Casallas PE, Bridges RS. Reproductive experience increases striatal and hypothalamic dopamine levels in pregnant rats. Brain Res Bull 1996; 40: 253-256.

20. Pellow S, Chopin P, File SE, Briley M. Validation of open:closed arm entries in an elevated plus-maze as a measure of anxiety in the rat. $J$ Neurosci Methods 1985; 14 : 149-167.

21. Lister RG. The use of a plus-maze to measure anxiety in the mouse. Psychopharmacology 1987; 92: 180-185.

22. Fraser LM, Brown RE, Hussin A, Fontana M, Whittaker A, O'Leary TP, et al. Measuring anxiety- and locomotionrelated behaviours in mice: a new way of using old tests. Psychopharmacology 2010; 211: 99-112.

23. Clement $Y$, Le Guisquet AM, Venault P, Chapouthier G, Belzung $C$. Pharmacological alterations of anxious behaviour in mice depending on both strain and the behavioural situation. PLoS One 2009; 4: e7745.

24. Treit $D$, Fundytus $M$. Thigmotaxis as a test for anxiolytic activity in rats. Pharmacol Biochem Behav 1988; 31: 959962.

25. Bubar MJ, Pack KM, Frankel PS, Cunningham KA. Effects of dopamine D1- or D2-like receptor antagonists on the hypermotive and discriminative stimulus effects of (+)-MDMA. Psychopharmacology 2004; 173: 326-336. 
26. Dawson GR, Crawford SP, Collinson N, Iversen SD, Tricklebank MD. Evidence that the anxiolytic-like effects of chlordiazepoxide on the elevated plus maze are confounded by increases in locomotor activity. Psychopharmacology 1995; 118: 316-323.

27. Fletcher PJ, Korth KM, Robinson SR, Baker GB. Multiple 5-HT receptors are involved in the effects of acute MDMA treatment: studies on locomotor activity and responding for conditioned reinforcement. Psychopharmacology 2002; 162: 282-291.

28. Blanchard DC, Griebel G, Blanchard RJ. Conditioning and residual emotionality effects of predator stimuli: some reflections on stress and emotion. Prog Neuropsychopharmacol Biol Psychiatry 2003; 27: 1177-1185.

29. Blanchard R, Blanchard DC. Ethological models of fear and angry aggression. Clin Neuropharmacol 1986; 9 (Suppl 4): 383-385.

30. Blanchard DC, Griebel G, Blanchard RJ. The Mouse Defense Test Battery: pharmacological and behavioral assays for anxiety and panic. Eur J Pharmacol 2003; 463: 97-116.

31. Maldonado E, Navarro JF. MDMA ("ecstasy") exhibits an anxiogenic-like activity in social encounters between male mice. Pharmacol Res 2001; 44: 27-31.

32. Tanaka M, Kohno Y, Nakagawa R, Ida Y, Takeda S, Nagasaki $\mathrm{N}$. Time-related differences in noradrenaline turnover in rat brain regions by stress. Pharmacol Biochem Behav 1982; 16: 315-319

33. limori K, Tanaka M, Kohno Y, Ida Y, Nakagawa R, Hoaki Y, et al. Psychological stress enhances noradrenaline turnover in specific brain regions in rats. Pharmacol Biochem Behav 1982; 16: 637-640.

34. Onur OA, Walter H, Schlaepfer TE, Rehme AK, Schmidt C, Keysers $\mathrm{C}$, et al. Noradrenergic enhancement of amygdala responses to fear. Soc Cogn Affect Neurosci 2009; 4: 119126.

35. de la Mora MP, Gallegos-Cari A, Arizmendi-Garcia Y, Marcellino $\mathrm{D}$, Fuxe K. Role of dopamine receptor mechanisms in the amygdaloid modulation of fear and anxiety: Structural and functional analysis. Prog Neurobiol 2010; 90: 198-216.

36. Graham DR, Sidhu A. Mice expressing the A53T mutant form of human alpha-synuclein exhibit hyperactivity and reduced anxiety-like behavior. J Neurosci Res 2010; 88: 1777-1783.

37. Pena-Oliver Y, Buchman VL, Stephens DN. Lack of involvement of alpha-synuclein in unconditioned anxiety in mice. Behav Brain Res 2010; 209: 234-240.

38. de Kloet ER, Rosenfeld P, Van Eekelen JA, Sutanto W, Levine S. Stress, glucocorticoids and development. Prog Brain Res 1988; 73: 101-120.

39. Pacifici R, Zuccaro P, Farre M, Pichini S, Di Carlo S, Roset $\mathrm{PN}$, et al. Immunomodulating activity of MDMA. Ann N Y Acad Sci 2000; 914: 215-224.

40. Blanchard DC, Blanchard RJ. What can animal aggression research tell us about human aggression? Horm Behav 2003; 44: 171-177. 